\title{
Activated Porous Carbon Nanofibers for High-Performance Supercapacitors
}

\author{
Moyinul Islam, Xing $\mathrm{Lu}^{*}$ \\ State Key Laboratory of Materials Processing and Die \& Mold Technology, School of Materials \\ Science and Engineering, Huazhong University of Science and Technology, Wuhan 430074, P. R. \\ China \\ *E-mail: 1ux@hust.edu.cn
}

doi: $10.20964 / 2019.03 .01$

Received: 23 November 2018 / Accepted: 27 December 2018 / Published: 10 March 2019

\begin{abstract}
The pursuit of high-capacitance carbon materials is urgently needed for supercapacitors, which are among the most promising energy storage devices. Herein, we developed an effective $\mathrm{KOH}$-activation method to improve the porous structures of electrospun carbon nanofibers for high-performance supercapacitors. In detail, polyacrylonitrile (PAN) and polymethyl methacrylate (PMMA) polymer blend solutions were electrospun to fabricate carbon nanofibers for pure PAN and, PAN:PMMA (80:20). PMMA was used as a sacrificial polymer to create pores. Furthermore, the $\mathrm{KOH}$-activation method was applied to improve the pores of PAN:PMMA $(80: 20)$ at $600^{\circ} \mathrm{C}$. The obtained $\mathrm{KOH}$-activated PAN:PMMA (80:20) exhibits an excellent specific capacitance of $440 \mathrm{~F} \mathrm{~g} \mathrm{~g}^{-1}$ at a current density of 0.25 $\mathrm{A} \mathrm{g}^{-1}$ and a superior cycling stability of $95 \%$ after 5000 cycles. The present research contributes to the implementation of $\mathrm{KOH}$-activation that results in excellent performance compared to carbon nanofibers reported thus far. Our work demonstrates that $\mathrm{KOH}$-activation is an outstanding method to promote the performance of supercapacitors. Therefore, such a strategy could be a promising method to fabricate high-performance supercapacitors.
\end{abstract}

Keywords: Activation, Carbon nanofibers, Supercapacitors

\section{FULL TEXT}

(C) 2019 The Authors. Published by ESG (www.electrochemsci.org). This article is an open access article distributed under the terms and conditions of the Creative Commons Attribution license (http://creativecommons.org/licenses/by/4.0/). 